\title{
Anesthetic review of emergency peripartum hysterectomy following vaginal and cesarean delivery: a retrospective study
}

\author{
In Ho Lee ${ }^{1,2}$, Ju Hyung Son ${ }^{1}$, Young Chul Shin ${ }^{1,2}$, Jae Hoon Byun ${ }^{1}$, Hea Jo Yoon ${ }^{1}$, and Young Seok Jee ${ }^{1,2}$ \\ Department of Anesthesiology and Pain Medicine, ${ }^{1}$ Cheil General Hospital and Women's Healthcare Center, ${ }^{2}$ Kwandong University \\ College of Medicine, Seoul, Korea
}

Background: The purpose of this study was to review incidence, indications, complications, and the anesthetic management of emergency obstetric hysterectomies.

Methods: This was a retrospective study of the cases of emergency obstetric hysterectomies performed at the Woman's Hospital over a 3 year period between January 2008 and December 2010. The indication for surgery, anesthetic management, operating time, estimated blood loss, pre- and postoperative hemoglobin and hematocrit values, need for blood transfusion, and perioperative complications were obtained.

Results: During the study period there were 46 emergency obstetric hysterectomies for 20147 deliveries, giving an incidence of 2.28/1000 deliveries. The number of emergency hysterectomies was significantly higher with the cesarean deliveries than with the vaginal deliveries. The most common indication for emergency obstetric hysterectomy was placenta accreta. Postoperatively, Dissemimated Intravascular Coagulation (DIC) was the most common complication.

Conclusions: Abnormal placenta has been an main indication of emergency hysterectomy. Anesthesiologists should be eligible to aware of high risk of emergency hysterectomy and deal with massive hemorrhage. (Korean J Anesthesiol 2012; 63: 43-47)

Key Words: Anesthesiologists, Emergency obstetric hysterectomy, Massive hemorrhage, Placenta accreta.

\footnotetext{
Received: October 25, 2011. Revised: 1st, December 10, 2011; 2nd, January 18, 2012. Accepted: January 20, 2012.

Corresponding author: In Ho Lee, M.D., Department of Anesthesiology and Pain Medicine, Cheil General Hospital and Women's Healthcare Center, 1-19, Mukjeong-dong, Jung-gu, Seoul 100-380, Korea. Tel: 82-2-2000-7822, Fax: 82-2-2000-7785, E-mail: kmh1201h@paran.com (c) This is an open-access article distributed under the terms of the Creative Commons Attribution Non-Commercial License (http:// creativecommons.org/licenses/by-nc/3.0/), which permits unrestricted non-commercial use, distribution, and reproduction in any medium, provided the original work is properly cited.
} 


\section{Introduction}

Emergency peripartum hysterectomy (EPH) is one of the most fatal obstetric complications. It has been associated with maternal morbidity or mortality and accepted as a life-saving procedure for patients in cases of intractable hemorrhage. In the past, it has been used to prevent fatal hemorrhage caused by uterine atony and uterine rupture $[1,2]$. However, it has been increasingly used to prevent obstetric complications due to abnormal placenta (placental previa, accreta). This is associated with an increase in maternal previous history of cesarean delivery, operation for leiomyoma or other uterine surgery, elderly pregnancy and maternal smoking $[3,4]$.

The purpose of this study is to provide information for fast and safe anesthetic management to mothers requiring emergency hysterectomy by investigating the factors that make an emergency hysterectomy, differences in the frequency of emergency hysterectomy between vaginal and cesarean delivery, complications of massive bleeding and intraoperative anesthetic management.

\section{Materials and Methods}

We retrospectively analyzed 46 cases of emergency cesarean hysterectomy performed for 3 years between January 1, 2008 to December 31, 2010. All the patients that underwent EPH were identified from labour ward registers, and anesthesia

Table 1. Incidence of Emergency Peripartum Hysterectomy According to the Mode of Delivery

\begin{tabular}{cccc}
\hline Mode of delivery & No. & No. of EPH & EPH/delivery (\%) \\
\hline Vaginal & 12413 & 8 & 0.064 \\
C-sec & 7734 & 38 & $0.491^{*}$ \\
\hline
\end{tabular}

The values are number of patients. EPH: emergency obstetric hysterectomy, C-sec: cesarean section. $* \mathrm{P}<0.001$ between groups.

Table 2. Distribution of Cases by Age and Parity

\begin{tabular}{|c|c|}
\hline & Number of patients (\%) \\
\hline \multicolumn{2}{|l|}{ Age } \\
\hline $26-30$ & $1(2.2 \%)$ \\
\hline $31-35$ & $23(50 \%)$ \\
\hline $36-40$ & $18(39 \%)$ \\
\hline $41-45$ & $4(8.8 \%)$ \\
\hline \multicolumn{2}{|l|}{ Parity } \\
\hline Nulliparous & $16(34.7 \%)$ \\
\hline Parous 1 & $12(26 \%)$ \\
\hline 2 & $14(30.4 \%)$ \\
\hline$>3$ & $4(8.9 \%)$ \\
\hline
\end{tabular}

The values are number of patients. sheets recorded during the operation. EPH was defined as hysterectomy performed for hemorrhage unresponsive to other treatment within 24 hours of vaginal or cesarean delivery. Maternal characteristics such as age, parity, previous cesarean section and other history of gynecologic operations were recorded.

The indication for surgery, anesthetic management, operating time, estimated blood loss, pre- and postoperative hemoglobin and hematocrit values, need for blood transfusion, and perioperative complications were obtained.

Statistical analysis was performed using Sigmastat 3.0 (SPSS Inc., Chicago, IL, USA). The chi-square test was used for comparing vaginal and cesarean deliveries for the frequency of hysterectomies. P value $<0.05$ was considered statistically significant.

\section{Results}

A total of $46 \mathrm{EPH}$ out of 20147 deliveries were conducted during the study period. The number of emergency hysterectomies was significantly higher with the cesarean deliveries than with the vaginal deliveries $(\mathrm{P}<0.001$, Table 1$)$. With regards to age, women in their thirties were the most common and parous mothers were more common than nulliparous in the parity (Table 2). For past operation history, 27 cases of 46 (59\%) had undergone prior uterine surgery. Of these 27 cases, 16 had undergone a previous cesarean section, whereas 11 had undergone gynecologic surgery other than cesarean delivery. The most common indication for emergency obstetric hysterectomy was placenta accreta with/without previa (Table 3). General anesthesia was required in 45 mothers (97\%) and 31 cases of them with initially satisfactory regional anesthesia required intraoperative induction of general anesthesia with intubation. Mean blood loss was 5,642 $\mathrm{ml}$ and mean transfused packed RBC was 12 units (Table 4).

DIC was the most common perioperative complication and there was no maternal death and reexploration (Table 5). Most febrile patients responded to conservative care. Average hospital stay was 10.4 days.

Table 3. Indication of Emergency Obstetric Hysterectomy Encountered in this Study

\begin{tabular}{lc}
\hline & Number of patient (\%) \\
\hline Placenta accreta (with/without previa) & $25(18 / 7)(54.3 \%)$ \\
Uterine atony & $14(30.4 \%)$ \\
Uterine rupture & $3(6.5 \%)$ \\
Placenta previa (only) & $2(4.3 \%)$ \\
Abruptio placenta & $2(4.3 \%)$ \\
\hline
\end{tabular}


Table 4. Anesthetic and Operative Management

\begin{tabular}{lc}
\hline & Number of patients (\%) \\
\hline Anesthetic technique & 14 \\
General & 31 \\
Regional and general & 1 \\
Spinal & $189(100-390)$ \\
Operative time (min) & $5,642(1,100-21,000)$ \\
Estimated blood loss $(\mathrm{ml})$ & 37 \\
Intraoperative hypotension & $12(0-31)$ \\
Mean units transfused & $10(0-30)$ \\
Packed RBC & $11.1 \mathrm{~g} / \mathrm{dl} / 32 \%$ \\
FFP & $10.2 \mathrm{~g} / \mathrm{dl} / 29.2 \%$ \\
Mean preop. Hb./Hct. & \\
Mean postop. Hb./Hct. &
\end{tabular}

Data are mean (range) , number of patients (\%), Hypotension means systolic blood pressure less than $90 \mathrm{mmHg}$. RBC: red blood cells, FFP: fresh frozen plasma, Hb: hemoglobin, Hct: hematocrit.

\section{Discussion}

In this study, the incidence rate of hysterectomy after cesarean section $(0.491 \%)$ was higher than what was seen in a previous report $(0.11 \%)$ [5]. This increase may be due to intractable hemorrhage following cesarean section (CS) along with a global rise in CS rates [6].

In our study, the incidence of emergency hysterectomy after CS $(0.491 \%)$ was 13 -fold higher than after vaginal delivery (0.064\%), which is consistent with another study [7]. An especially high CS rate (38\% [7734/20147 deliveries]) in our hospital compared to another country [6] is regarded as an increasing factor of EPH because emergency obstetric hysterectomies are closely related to cesarean deliveries.

Postpartum hemorrhage (PPH) can be categorized as an abnormality of one or more of the following: uterine tone (uterine atony), retained tissue (placental tissue or blood clots), trauma (genital tract lacerations), or coagulation (coagulopathy) [8]. The most common indication for peripartum hysterectomy in our series was placenta accreta (54.3\%). This occurs when the placenta is unusually adherent to the defective decidua basalis or even to the myometrium and may induce massive hemorrhage together with uterine atony, which is a serious problem for obstetric anesthesiologists [9]. On the other hand, previous studies showed that the most common indication for peripartum hysterectomy was uterine atony $[2,10]$. The higher CS rate and more successful conservative treatment of uterine atony with uterotonic agents (especially prostaglandin analogues) and operative interventions explain the differences between the previous studies and the present one [11].

Several surgical methods are useful to reduce hemorrhage during surgery for placenta accreta. Internal iliac vessel ligation is described as a technique for reducing hemorrhage prior to delivery of the placenta [12]. Failure to use this technique
Table 5. Perioperative Complications Experienced in this Study

\begin{tabular}{lc}
\hline & Number of patients \\
\hline DIC & 32 \\
Pulmonary edema & 15 \\
Fever & 8 \\
Bladder laceration & 6 \\
Atelectasis & 5 \\
Hematoma & 4 \\
Ileus & 2 \\
Amniotic fluid embolism & 1 \\
Pelvic abscess & 1 \\
Hydronephrosis & 1 \\
Reexploration & 0 \\
Maternal mortality & 0 \\
\hline
\end{tabular}

The values are number of patients. Fever was defined by oral temperatures higher than $38^{\circ} \mathrm{C}$.

prior to placental delivery or unfamiliarity with this technique may contribute to maternal mortality [12]. Angiographic arterial embolization of uterine arteries or ovarian arteries is of significant value in treating obstetric hemorrhage with the cooperation of emergency interventional radiology service [13]. Conservative treatment (closure of the uterus and abdomen without removing the placenta) may reduce intra-operative bleeding but delayed hemorrhage and postpartum sepsis may occur $[12,14]$.

Failure of the placenta to separate easily resulted in massive and sometimes uncontrolled haemorrhage. In particular, further attempts to remove the placenta accreta at this point may cause catastrophic hemorrhage. In the face of hypovolemic shock, the cardinal principle is rapid restoration of effective intravascular volume and adequate oxygen carrying capacity to ensure tissue oxygenation. We must keep in mind that potential problems such as coagulopathy, hypothermia, leftward shift in the oxyhemoglobin dissociation curve, acid-base imbalance, electrolyte abnormalities and infection can occur with massive transfusion. Especially in the case of DIC, if epidural catheter is already placed in the epidural space, the epidural catheter should be removed when the patient's coagulation status is normal, or back to baseline for avoiding possible epidural hematoma [9].

Hysterectomy is often the definitive treatment for $\mathrm{PPH}$ and can be a technically challenging operation due to the enlarged uterus, engorged vessels, and edematous tissues [15]. If alternative interventions fail, hysterectomy should not be delayed in patients that continue to bleed. Prompt control of uterine hemorrhage is vital to decrease morbidity and prevent death, as continued blood loss can lead to disseminated intravascular coagulation (DIC) [16].

In the selection of anesthetic agents undergoing cesarean hysterectomy, general anesthesia is frequently indicated and 
considered preferable. Prolonged operation time predisposes the patient to restlessness and general discomfort. Intraperitoneal manipulation and traction may result in pain, nausea, and involuntary retching. Hyperemic pelvic viscera with engorged, edematous vasculature require careful dissection facilitated by a quiet operative field $[17,18]$.

Also, there is a report about airway change during cesarean hysterectomy [19]. A change in airway status has two important clinical implications in the management of parturient for peripartum hysterectomy. First, intraoperative induction of general anesthesia may be required in patients undergoing peripartum hysterectomy under regional anesthesia any time during the course of the procedure and, secondly, general anesthesia may be required to facilitate re-operation to explore and control excessive postoperative hemorrhage. It may be prudent to induce general anesthesia and secure the airway as soon as substantial hemorrhage requiring large volume infusion/transfusion is anticipated. On the other hand, if the airway is not secured, periodic assessment of the airway during the course of surgery is recommended to determine worsening of the airway [19].

A significant percentage of parturients with hemorrhagic shock experienced electrocardiographic signs of ischemia and decreased contractility that correlated with the severity of hemorrhage [20]. Therefore, the therapeutic goal in the treatment of severe $\mathrm{PPH}$ is avoidance of myocardial ischemia by increasing the myocardial supply-demand ratio [16].

Placenta accreta may be suspected prior to surgery, but the actual diagnosis is only confirmed at surgery. Pre-operative preparation of patients suspected of having placenta accreta is important given the potential for rapid and massive blood loss. We must be careful for high risk patients (previous cesarean section, placenta accreta with/without previa) as seen in our study. Anterior position of the placenta in ultrasound performed within 2 month of delivery was most common, observed in 28 cases $(61 \%)$ among patients that underwent emergency obstetric hysterectomy in our study.

We insert at least two large gauge IV cannulae for both high and low suspicious accreta cases prior to the start of surgery and cross matched blood must be readily available at the beginning of surgery.

When an uncontrolled hemorrhage occurs, anesthetic management starts with the evaluation of airway and oxygenation, and establishment of large-bore intravenous access. Blood and fluid replacement can be guided by assessment of the amount of blood in the suction canisters, along with heart rate, urine output and systemic invasive blood pressure. We must keep in mind that most maternal morbidity and mortality is due to underestimation of blood loss, inadequate volume replacement and delay in intervention [16]. It is important that rapid fluid infusion is more important than the choice of fluid or immediate hemodynamic monitoring. Also, prompt communication between anesthesiology, obstetric-gynecology, nursing, laboratory, and blood bank is essential for effective evaluation and management of excessive blood loss [21].

In conclusion, the incidence rate of hysterectomy after cesarean section continues its upward trend and placenta accreta is emerging as an important risk factor for emergency postpartum hysterectomy. Peripartum hysterectomy is a life saving procedure that is associated with high maternal morbidity and anesthesiologists should be aware of management options when dealing with significant hemorrhage.

\section{References}

1. Chestnut DH, Eden, RD, Gall SA, Parker RT. Peripartum Hysterectomy: a review of cesarean and postpartum hysterectomy. Obstet Gynecol 1985; 65: 365-70.

2. Clark SL, Yeh SY, Phelan JP, Bruce S, Paul RH. Emergency Hysterectomy for Obstetric haemorrhage. Obstet Gynecol 1984; 64: 376-80.

3. Stanco LM, Schrimmer DB, Paul RH, Mishell DR Jr. Emergency Peripartum hysterectomy and associated risk factors. Am J Obstet Gynecol 1993; 168: 879-83.

4. Zelop CM, Harlow BL, Frigoletto FD Jr, Safon LE, Saltzman DH. Emergency peripartum hysterectomy. Am J Obstet Gynecol 1993; 168: 1443-8.

5. Park HJ, Kim IH, Kim NS, Cha DS, Kim MC, Han SW, et al. A clinical study on cesarean hysterectomy. Korean J Obstet Gynecol 1997; 40: 1954-60.

6. Yoong W, Massiah N, Oluwu A. Obstetric hysterectomy: changing trends over 20 years in a multiethnic high risk population. Arch Gynecol Obstet 2006; 274: 37-40.

7. Smith J, Mousa HA. Peripartum hysterectomy for primary postpartum haemorrhage: incidence and maternal morbidity. J Obstet Gynaecol 2007; 27: 44-7.

8. Devine PC. Obstetric haemorrhage. Semin Perinatol 2009; 33: 7681.

9. Terui K. Antepartum hemorrhage. In: Textbook of Obstetric Anesthesia. Edited by Birnbach DJ, Gatt SP, Datta S: Philadelphia, Churchill livingstone Publishers. 2000, pp 405-8.

10. Kim SY, Kim MH, Cho KS, Cho DH, Kim MK. Anesthetic management for emergency obstetric hysterectomy. Korean J Anesthesiol 1995; 28: 164-70.

11. Awan N, Bennett MJ, Walters WA. Emergency peripartum hysterectomy: a 10-year review at the Royal Hospital for Women, Sydney. Aust N Z J Obstet Gynaecol 2011; 51: 210-5.

12. O'Brien JM, Barton JR, Donaldson ES. The management of placenta percreta: conservative and operative strategies. Am J Obstet Gynecol 1996; 175: 1632-8.

13. Ojala K, Perala J, Kariniemi J, Ranta P, Raudaskoski T, Tekay A. Arterial embolization and prophylactic catheterization for the treatment for severe obstetric haemorrhage*. Acta Obstet Gynecol Scand 2005; 84: 1075-80.

14. Kayem G, Davy C, Goffinet F, Thomas C, Clement D, Cabrol D. 
Conservative versus extirpative management in cases of placenta accreta. Obstet Gynecol 2004; 104: 513-6.

15. Mayer DC, Smith KA. Chestnut's Obstetric anaesthesia principles and practice. 4th ed. Missouri, Elsevier Mosby. 2009, pp 825-30.

16. Walfish M, Neuman A, Wlody D. Maternal haemorrhage. Br J Anaesth 2009; 103 Suppl 1: i47-56.

17. LaPlatney DR, O'Leary J. Anesthetic considerations in cesarean hysterectomy. Anesth Analg 1970; 49: 328-30.

18. Chestnut DH, Redick LF. Continuous epidural anesthesia for elective cesarean hysterectomy. South Med J 1985; 78: 1168-9.
19. Bhavani-Shankar K, Lynch EP, Datta S. Airway changes during Cesarean hysterectomy. Can J Anaesth 2000; 47: 338-41.

20. Karpati PC, Rossignol M, Pirot M, Cholley B, Vicaut E, Henry P, et al. High incidence of myocardial ischemia during postpartum haemorrhage. Anesthesiology 2004; 100: 30-6.

21. American College of Obstetricians and Gynecologists. ACOG Practice Bulletin: Clinical Management Guidelines for ObstetricianGynecologists Number 76, October 2006: postpartum hemorrhage. Obstet Gynecol 2006; 108: 1039-47. 